\title{
Seismological constraints for the dike emplacement of July-August 2001 lateral eruption at Mt. Etna volcano, Italy
}

\author{
Domenico Patanè $\left({ }^{1}\right)$, Eugenio Privitera $\left({ }^{1}\right)$, Stefano Gresta $\left({ }^{2}\right)$, Aybige Akinci $\left({ }^{3}\right)$, Salvatore Alparone $\left({ }^{1}\right)$, \\ Graziella Barberi $\left({ }^{1}\right)$, Lauro Chiaraluce $\left({ }^{3}\right)$, Ornella Cocina $\left({ }^{1}\right)$, Salvatore D'Amico $\left({ }^{1}\right)$, \\ Pasquale De Gori $\left({ }^{3}\right)$, Giuseppe Di Grazia $\left({ }^{1}\right)$, Susanna Falsaperla $\left({ }^{1}\right)$, Ferruccio Ferrari $\left({ }^{1}\right)$, \\ Salvatore Gambino $\left({ }^{1}\right)$, Elisabetta Giampiccolo $\left({ }^{1}\right)$, Horst Langer $\left({ }^{1}\right)$, Vincenza Maiolino $\left({ }^{1}\right)$, \\ Milena Moretti $\left({ }^{3}\right)$, Antonino Mostaccio $\left({ }^{1}\right)$, Carla Musumeci $\left({ }^{1}\right)$, Davide Piccinini $\left({ }^{3}\right)$, \\ Danilo Reitano $\left({ }^{1}\right)$, Luciano Scarfi $\left({ }^{1}\right)$, Salvatore Spampinato $\left({ }^{1}\right)$, Andrea Ursino $\left({ }^{1}\right)$ \\ and Luciano Zuccarello ${ }^{(1)}$ \\ ( $\left.{ }^{1}\right)$ Istituto Nazionale di Geofisica e Vulcanologia, Sezione di Catania, Italy \\ (2) Dipartimento di Scienze Geologiche, Università di Catania, Italy \\ (3) Istituto Nazionale di Geofisica e Vulcanologia, Sezione di Roma, Italy
}

\begin{abstract}
In this paper we report seismological evidence regarding the emplacement of the dike that fed the July 18 - August 9, 2001 lateral eruption at Mt. Etna volcano. The shallow intrusion and the opening of the eruptive fracture system, which mostly occurred during July 12 , and July 18 , were accompanied by one of the most intense seismic swarms of the last 20 years. A total of 2694 earthquakes $\left(1 \leq M_{d} \leq 3.9\right)$ were recorded from the beginning of the swarm (July 12) to the end of the eruption (August 9). Seismicity shows the upward migration of the dike from the basement to the relatively thin volcanic pile. A clear hypocentral migration was observed, well constraining the upwards propagation of a near-vertical dike, oriented roughly $\mathrm{N}-\mathrm{S}$, and located a few kilometers south of the summit region. Earthquake distribution and orientation of the $P$-axes from focal mechanisms indicate that the swarm was caused by the local stress source related to the dike intrusion.
\end{abstract}

Key words Mt. Etna - 2001 eruption - seismicityfault plane solutions - dike intrusion

\section{Introduction}

The study of seismic activity is a powerful tool for understanding both the inner structure of a volcano and its eruptive behavior. Over the last 30 years, seismic data collected at Mt. Etna volcano have provided information on both the dynamics and structure of the volcano. The most evident consideration regarding the

Mailing address: Dr. Domenico Patanè, Istituto Nazionale di Geofisica e Vulcanologia, Sezione di Catania, P.zza Roma 2, 95123 Catania, Italy; e-mail: patane@ct.ingv.it volcano's behavior before, during and after an eruption originates from the analysis of spacetime distribution and fault plane solutions of earthquakes. A general observation is that summit eruptions are not preceded by a seismic crisis; whereas lateral eruptions are usually preceded by a 1-2 day seismic crisis (e.g., Gresta and Patanè, 1987; Ferrucci and Patanè, 1993).

In such a case, only the smallest and shallowest events have generally occurred close to the eruptive fissure, the largest shocks being spread over much larger areas than the eruptive ones (e.g., Gresta and Patanè, 1987). An example of such behavior was given during the onset of the December 1985 and the October 1986 - February 1987 eruptions. The two eruptive fractures opened on the eastern side of the volcano, in Valle del Bove and Valle del Leone calderas, respectively. 
Simultaneously with their opening, two shocks (both of magnitude 3.8-4.0) occurred, about 7 $\mathrm{km}$ away on the northeastern side, along the Provenzana-Pernicana fault system (Gresta, 1995). Also the strongest $\left(M_{d}=4.5\right)$ earthquake, recorded during the swarm accompanying the onset of the 1991-1993 eruption, occurred several kilometers from the eruptive fissure (Ferrucci and Patanè, 1993; Bonaccorso et al., 1996). These case histories disclose that the seismic activation of fault systems at Mt. Etna often occurs as a response to accommodate deformations induced by the magma injection.

Further interpretation on the eruptive dynamics may be taken from Fault Plane Solutions (FPSs) and space-time migration of hypocenters, during the months preceding eruption onsets. For example, the 1991-1993 flank eruption was preceded by a change in the local stress field orientation (e.g., Patanè et al., 1994; Bonaccorso et al., 1996; Cocina et al., 1998). It was suggested that an upward migration of magma along the NNW-SSE structural trend and its intrusion into the upper crust was responsible for the rotation of the local stress field observed from FPSs of shocks at depths less than $10 \mathrm{~km}$ (Bonaccorso et al., 1996; Barberi et al., 2000; Patanè and Privitera, 2001). Seismicity that occurred before and during the 1991-1993 eruption along the seismogenic NE-SW structural trend, was considered to be the brittle response to magma intrusion along the NNW-SSE volcano-tectonic system. In fact, the occurrence of seismic swarms in the southwestern sector of the volcano along NE-SW trending structures has frequently been observed both before and during eruptions. Such swarms may be related to magma movements through the upper crust and/or inside the volcanic edifice. The same mechanism was observed in January 1998, during an intrusive event (Bonaccorso and Patanè, 2001), when, however, no lateral eruption occurred. Finally, a similar seismic swarm occurred between 20 and 24 April, 2001, three months before the July-August eruption.

This paper focuses on the July 12-18, 2001 seismic swarm which was one of the strongest (both in number and in cumulative energy of the shocks) recorded in the last 20 years at Mt. Etna volcano. During 2001, a total number of 37 seismic stations of the local permanent network, run by the Istituto Nazionale di Geofisica e Vulcanologia, Sezione di Catania (INGV-CT) were operating, eight of which equipped with three component seismometers (fig. 1). The network provided good data for the location of earthquakes with $M_{d} \geq 1.5$, enabling us to characterize the kinematics of the shallow magma intrusion and the opening of the eruptive fissure. The aim of this paper is to characterize and interpret the space-time evolution and kinematics of the seismicity preceding and accompanying the July 17 - August 9, 2001 lateral eruption.

\section{Pre-eruptive seismic and volcanic activity}

After the 1991-1993 major lateral eruption, activity at the summit craters of Mt. Etna (fig. 1) resumed in 1995 with a series of lava fountaining episodes. In particular, from the middle of 1998, there were quiet lava effusions and several spectacular sequences of explosive paroxysms (Research Staff of INGV-CT, 2001). Seismic activity revealed a change in the dynamic conditions acting on the volcano in late 2000 , about 8 months before the onset of the lateral eruption. On November 5, a seismic swarm occurred on the southern flank of Mt. Etna at a depth of about $8-10 \mathrm{~km}$. This event marked the beginning of a significant increase in the cumulative strain release curve (Bonaccorso et al., 2003).

From November 2000 to April 2001, seismic activity gradually increased both in number and average magnitude of events. The epicenters were spread over a wide area covering most of the southern and eastern part of the volcano (Bonaccorso et al., 2003). On April 20-24, 2001 a seismic swarm occurred with more than 200 events $\left(\max M_{d}=3.6\right)$. The hypocenters were distributed in the south-southwest upper part of the volcano, in the depth range $5-10 \mathrm{~km}$, clearly defining a NE-SW alignment (Bonaccorso et al., 2003).

From June 6, a series of eruptive episodes characterized by strong strombolian activity and lava overflows occurred at the South East Crater (SEC). By late July 12, a paroxysmal eruption, one of the most violent in the whole 


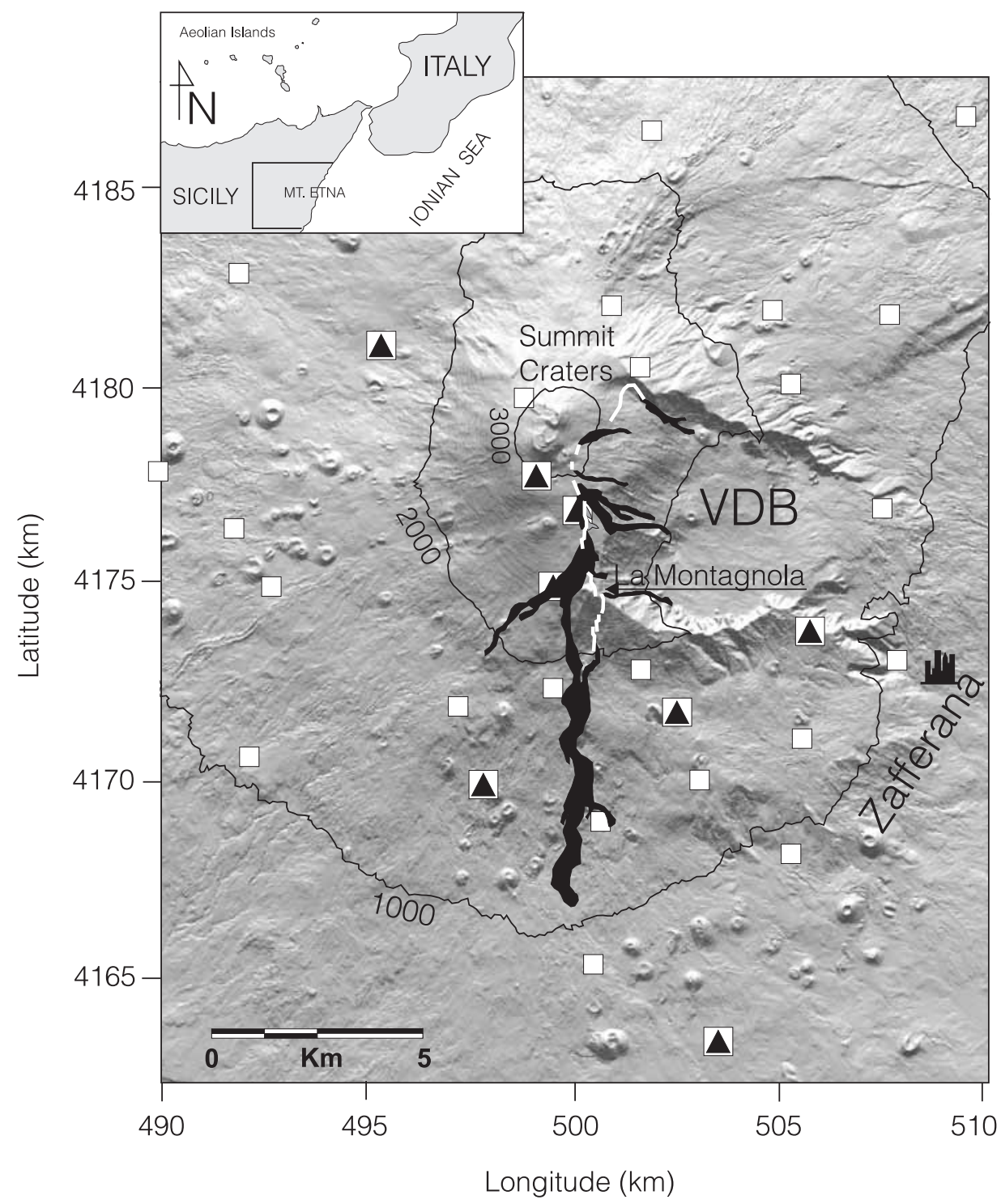

Fig. 1. Map of the central part of Mt. Etna volcano showing the location of seismic stations (white squares: 1-component stations; black triangles: 3-component stations) of the permanent INGV-CT network. Ground fractures (white line) that opened between July 12 and 17, and lava flows emplaced from July 18 to August 9 are also shown. VDB indicates the location of the Valle del Bove caldera.

series, was accompanied by the resumption of seismicity in the southern upper flank of the volcano, heralding the opening of non-eruptive (dry) ground fractures.
A further paroxysmal eruptive episode at the SEC occurred in the early morning of July 17. A few hours later, the highest part of a fracture originating from the southern base of the SEC 
became eruptive (fig. 1). This fracture gradually propagated downslope and bent south, producing mild strombolian activity and a lava flow that extended SSE. In the following hours, a second part of the fissure became eruptive north of La Montagnola (a large pyroclastic cone 2700 $\mathrm{m}$ a.s.1.) giving rise to a major lava flow that spread southward. In the early morning of July 18 at about 00:20 (all hours are quoted as GMT), further seismic events accompanied the opening of a third eruptive vent located south of La Montagnola, at about $2100 \mathrm{~m}$ a.s.l. Over the following days, explosive activity occurred and lava flows advanced slowly to the south. A total of six eruptive centres were active simultaneously along the complex fracture system. The eruption abated within two weeks and stopped completely on August 9, 2001 (Research Staff of INGV-CT, 2001).

\section{The July 12-18, 2001 swarm}

2694 earthquakes with $M_{d} \geq 1$ were recorded from July 12 (at 21:44) until the end of the eruption, but the great majority of them (2645 events) occurred before the onset of the magma outflow.

About 800 earthquakes were recorded in the first $15 \mathrm{~h}$ of the swarm. During this stage, a warning was issued and alert messages were sent to local and national Civil Defence Departments. After this initial phase, the hourly number of shocks showed a fluctuating decrease until July 18 , but the cumulative strain release gradient was almost constant (fig. 2). The highest magnitude observed during the swarm was 3.9, while only 62 earthquakes had $M_{d} \geq 3.0$.

Accurate digital picking of $P$ - and $S$-phases was performed ( $S$-phases were picked only at three-component stations). Earthquakes were located using the program HYPOELLIPSE (Lahr, 1989) to take into account the difference in elevation of the seismic stations and to accurately determine the spatial pattern of hypocenters in the volcanic cone. The $1 \mathrm{D}$ velocity model used was derived from Hirn et al. (1991), with the sea level assumed as the reference (zero) elevation.

Due to the low magnitude and shallowness, most of the events have good signal to noise

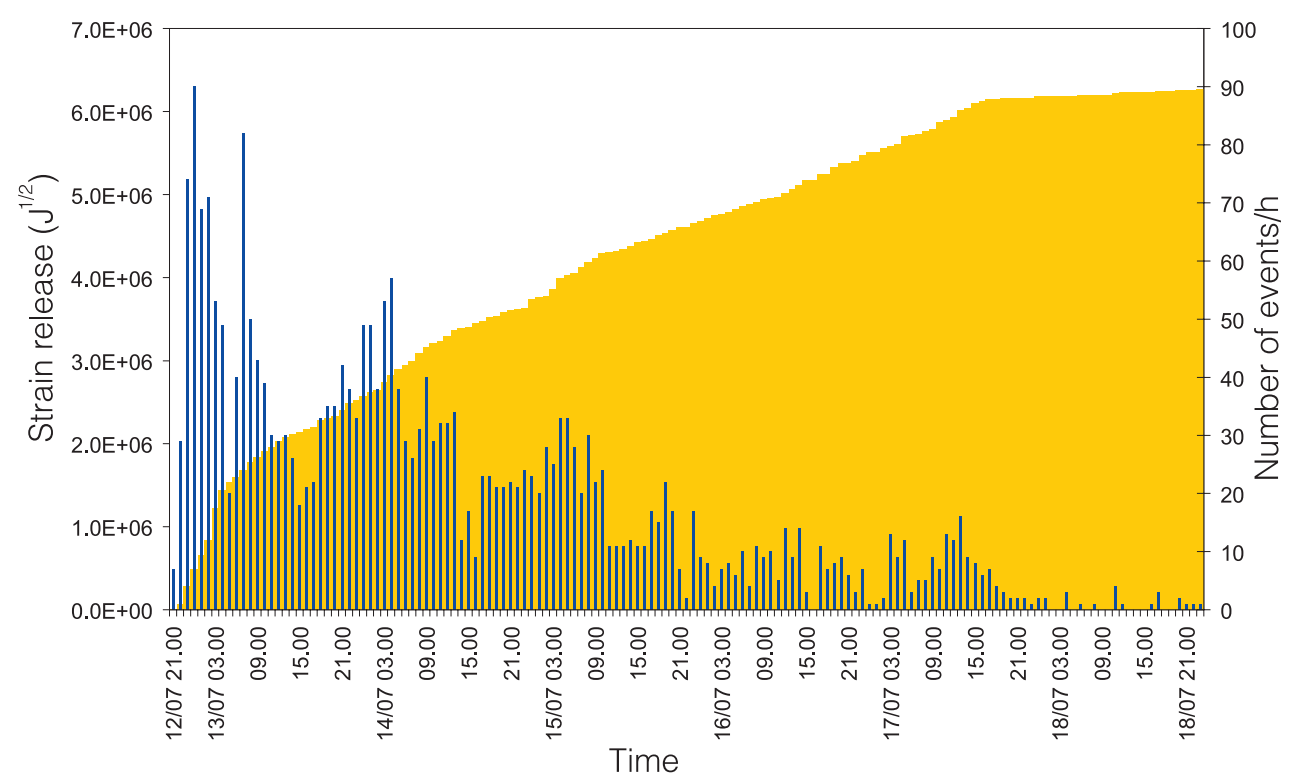

Fig. 2. Earthquake hourly rate and related strain release of the July 12-18 seismic swarm. 

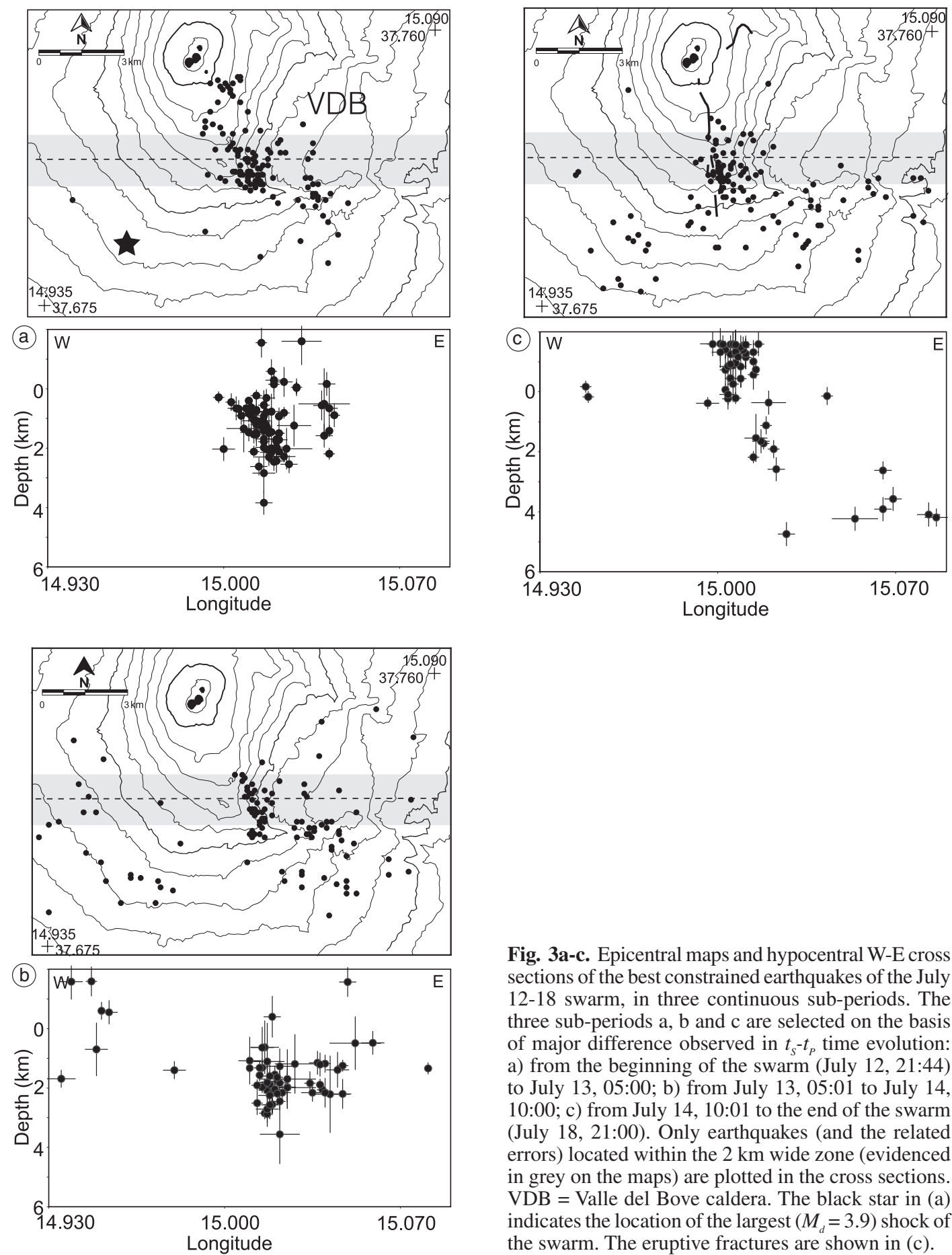

Fig. 3a-c. Epicentral maps and hypocentral W-E cross sections of the best constrained earthquakes of the July 12-18 swarm, in three continuous sub-periods. The three sub-periods a, b and c are selected on the basis of major difference observed in $t_{s}-t_{p}$ time evolution: a) from the beginning of the swarm (July 12, 21:44) to July 13, 05:00; b) from July 13, 05:01 to July 14, $10: 00$; c) from July $14,10: 01$ to the end of the swarm (July 18, 21:00). Only earthquakes (and the related errors) located within the $2 \mathrm{~km}$ wide zone (evidenced in grey on the maps) are plotted in the cross sections. VDB = Valle del Bove caldera . The black star in (a) indicates the location of the largest $\left(M_{d}=3.9\right)$ shock of the swarm. The eruptive fractures are shown in (c). 
ratio mainly at the closest stations. Moreover, first $P$-wave arrivals were often masked by the high tremor amplitude and/or the coda waves of a previous event.

In order to better examine the space-time foci migration, we selected the location data set by using the following criteria: number of observations $\geq 10$, erh $\leq 1 \mathrm{~km}$, erz $\leq 1.4$ $\mathrm{km}, \mathrm{rms} \leq 0.35 \mathrm{~s}$, gap $\leq 180^{\circ}$. The resulting data set consists of 337 events. A detailed analysis of $t_{S}-t_{p}$, at the three closest threecomponent stations was also performed, to better constrain the locations. On the basis of major difference observed in $t_{s}-t_{P}$ values, we selected three sub-periods to plot the foci distribution (fig. 3a-c): i) from the beginning of the swarm until 05:00 of July 13; ii) from July 13, 05:01 to July 14, 10:00; iii) from July 14, 10:01 until the end of the swarm (July 18, at 21:00). We focus our attention on the earthquakes that occurred in a two kilometer wide east-west elongated area where the main eruptive fissures developed (see fig. 3a-c). In the first period (fig. 3a), hypocentral depths ranged from 0 to $3 \mathrm{~km}$ b.s.l. A major cluster was found on the highest part of southern slope, aligned about NNW-SSE, from east of La Montagnola to the base of the summit craters. A second smaller cluster occurred at $0-2 \mathrm{~km}$ depth beneath the Valle del Bove. It is noteworthy that the strongest event of the whole sequence occurred $\mathrm{ca} .5$ $\mathrm{km}$ away from the main cluster (fig. 3a), on the volcano's southwestern flank at a depth of $c a$. $0.5 \mathrm{~km}$ a.s.1. In the second period (fig. $3 \mathrm{~b}$ ), seismicity along the NNW-SSE alignment clustered east of La Montagnola and was slightly deeper (1-3 km b.s.1.). Two other crustal volumes became seismically active to the west and to the east of the main earthquake cluster, respectively. The former was located in the SW flank of the volcano (depths ranging between $1 \mathrm{~km}$ a.s.l. and $2 \mathrm{~km}$ b.s.l.), and the latter was located on the southern rim of the Valle del Bove (depth ranging between 0 and $3 \mathrm{~km}$ b.s.l.). In the third period (fig. 3c), events migrated slightly westward and hypocenters clustered at shallower depths (from 2 $\mathrm{km}$ a.s.l. to the sea level). Earthquakes located to the west and to the east of the eruptive fractures maintained almost the same spatial features as observed during the second period; the only remarkable difference was the occurrence of shocks in the easternmost sector at depth of 3-6 km b.s.l. At 00:20 on July 18, a $M_{d}=3.0$ shock occurred in coincidence with the opening of an eruptive vent at $2100 \mathrm{~m}$ a.s.l. Thereafter, the earthquake activity decreased both in number of events and in magnitude. Afterwards, the only relevant seismic phenomenon was the enhanced amplitude of volcanic tremor that accompanied the eruption until the end.

\section{Focal mechanisms}

The earthquakes used to compute Fault Plane Solutions (FPSs) were characterized by high frequency content, sharp first arrivals and clear $S$-phases at the nearest stations. Therefore, a double couple source was assumed for these earthquakes.

The analysis was performed using the FPFIT algorithm (Reasenberg and Oppenheimer, 1985) to plot first motion data and to evaluate nodal planes and orientation of $P$ - and $T$-axes. The good azimuth coverage of the investigated area constrained single focal solutions for most of the events. A set of about 300 FPSs was obtained. In this study, we considered 47 of them, selected on the basis of rigorous criteria (number of polarities $\geq 10$, number of polarity discrepancies $\leq 2$, focal planes uncertainty $<20^{\circ}$, unique and unambiguous solution). In order to improve the reliability of the solutions, available $S$-wave polarization at 3 -component stations were jointly inverted with $P$-wave polarity data, using the probabilistic approach by Zollo and Bernard (1991) and De Natale et al. (1991).

Results indicated that most of the earthquakes had dominantly strike-slip rupture mechanisms. In several cases the strike-slip mechanisms have a remarkable normal component. Dip-slip mechanisms were also observed, mostly along the NNW-SSE alignment, in the seismogenic volumes located in the eastern sector. It is also noteworthy that a small number of reverse dipslip mechanisms was found. Figure 4 shows some examples of FPSs representative of the data set. We also analysed spatial distribution of the horizontal projection of the $P$-axes (fig. 4). $P$-axes directions were mostly distributed 


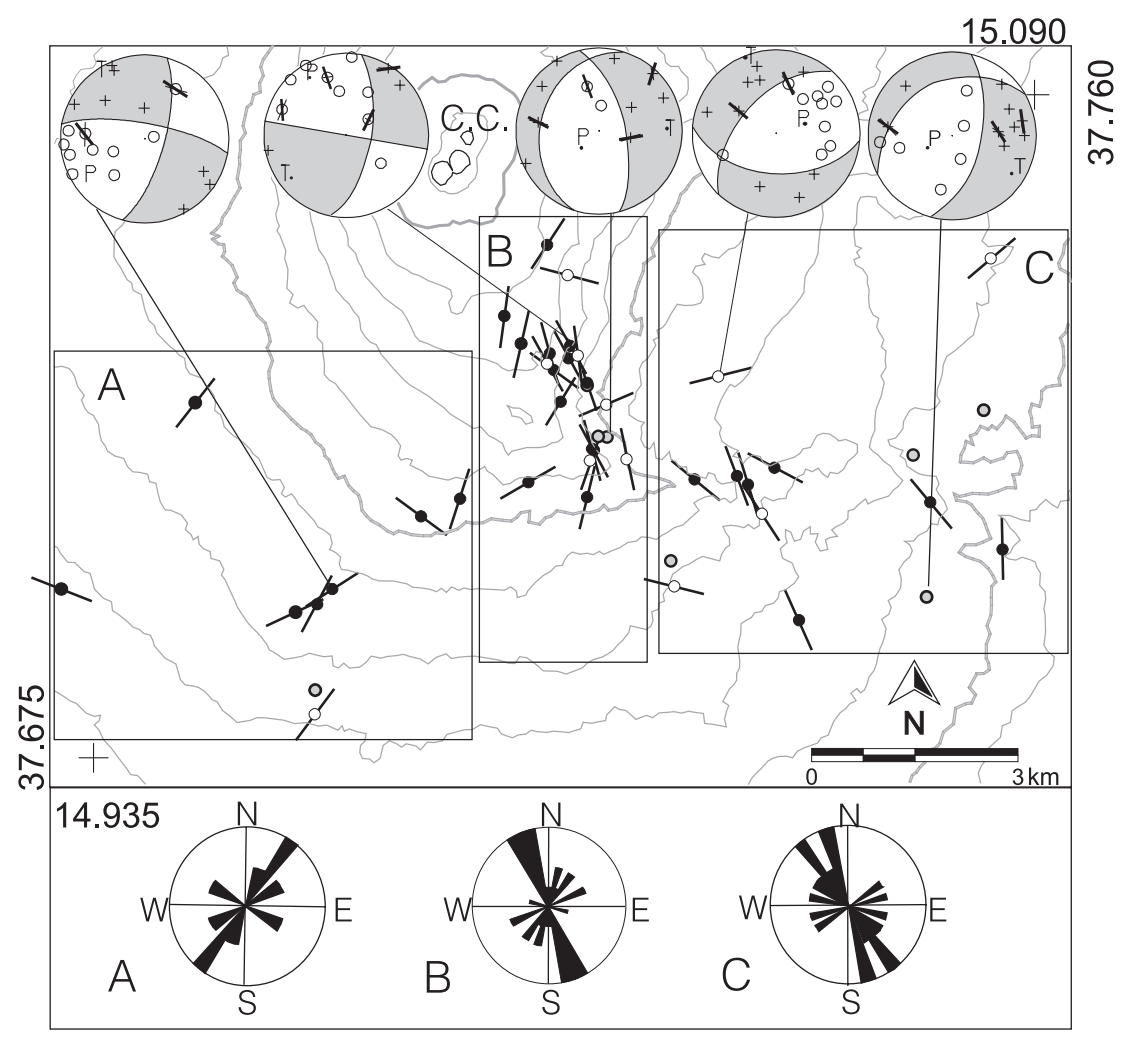

Fig. 4. Azimuth distribution of the horizontal projection of $P$-axes of 47 earthquakes selected from the swarm. Black circles mark axes with a dip of $0-30^{\circ}$, white circles mark axes with $31-60^{\circ}$, and grey circles represent nearly vertical axes $\left(61-90^{\circ}\right)$. The rose diagrams, related to the areas $\mathrm{A}, \mathrm{B}$ and $\mathrm{C}$, show the cumulative number of azimuth directions. Some representative FPSs examples of the data set are also shown. First motion data are projected onto lower hemisphere. The comparison between theoretical (thin line) and experimental (thick line) $S$-wave polarization, measured at three-component stations, is also shown on the FPSs.

sub-horizontally, showing that transtensive and strike-slip faults dominated the whole data-set.

Normal dip-slip mechanisms, about NNWSSE aligned (B in fig. 4), were also observed in the area near the main seismic cluster. A rose diagram shows a prevalence of $P$-axes with azimuth $\mathrm{N} 330^{\circ}-350^{\circ} \mathrm{E}$ in this area. Similar features were also observed in the eastern sector (area C of fig. 4). In the western sector (area A of fig. 4), the $P$-axes were oriented NE-SW, coherent with ground deformation data that indicated a similar orientation of the displacement vectors for this sector of the volcano (Research Staff of INGV-CT, 2001).

\section{Discussion and conclusions}

The seismological findings reported above disclose that brittle fractures accompanied the final stages of the dike intrusion driving the July-August 2001 lateral eruption at Mt. Etna. At the beginning, only the basement rocks fractured, then also the volcanic pile. Moreover, seismic data may help to constrain the mechanism of the intrusion.

The south-eastern flank of Mt. Etna is one of the weakest zones of the volcano where the emplacement of dikes during previous eruptions has occurred (e.g., Bonaccorso et al., 1996; Bonaccorso, 2001). 
The hypocenters of the July 12-18 swarm were located mainly along the NNW-SSE structural trend, at a depth between 0 and 3 $\mathrm{km}$ b.s.l. The deepest events were located east of the eruptive fractures, while the shallowest were located along these fractures (see figs. 1 and 3a-c). Overall, this swarm (fig. 3a-c) may represent the response of both the basement and the volcanic pile to the stress induced by the upward propagation of the dike. In particular, dike emplacement at depths ranging from 1 to $3 \mathrm{~km}$ b.s.l. occurred in the volcano basement, where the westernmost part of a high velocity (and rigidity) body is located (e.g., Chiarabba et al., 2000; Laigle et al., 2000; Patanè et al., 2002).

It should be noted that the thickness of the volcanic pile, which is characterized by poor mechanical properties, ranges from a few tens of meters in the peripheral areas of the volcano to about $2000 \mathrm{~m}$ below the summit craters (Rust and Neri, 1996). The sudden foci depth variation that occurred on July 14 (fig. 5) is indicative of the intersection of the upward-propagating dike with the volcanic pile. Moreover, we believe that earthquakes located as far as $6 \mathrm{~km}$ east and west of the main seismic cluster (fig. 3a-c) were caused by stress transfer induced by compression of the host rocks in response to the jerky dike inflation.

It has been observed worldwide that major tensile cracks and dikes are generally aligned in the direction of regional maximum compressive stress (e.g., Hill, 1977; Nakamura, 1977; Shaw, 1980), which for Mt. Etna area is oriented $c a$. N-S (Lanzafame et al., 1997; Cocina et al., 1998; Patanè and Privitera, 2001; among others). Thus the July 2001 eruptive fracture system is in good agreement with the direction of the regional maximum compressive stress. Similar evidence holds for the trend of the swarm seismicity.

It is worth recalling that magma intrusion is accompanied by different types of focal mechanisms (sometimes at short distances from each other), as observed for example at Hawaii (Thurber and Gripp, 1988) and at Mt. Usu (Matsumura et al., 1991). This is also the case at Mt. Etna in 2001. Strike-slip mechanisms dominate in the intrusive volume, and some transtensive and normal mechanisms are also present (area B in fig. 4). The observed normal faulting mechanisms may be explained by local stress from vertical dike propagation (resulting in sub-vertical $P$-axes), whereas horizontal

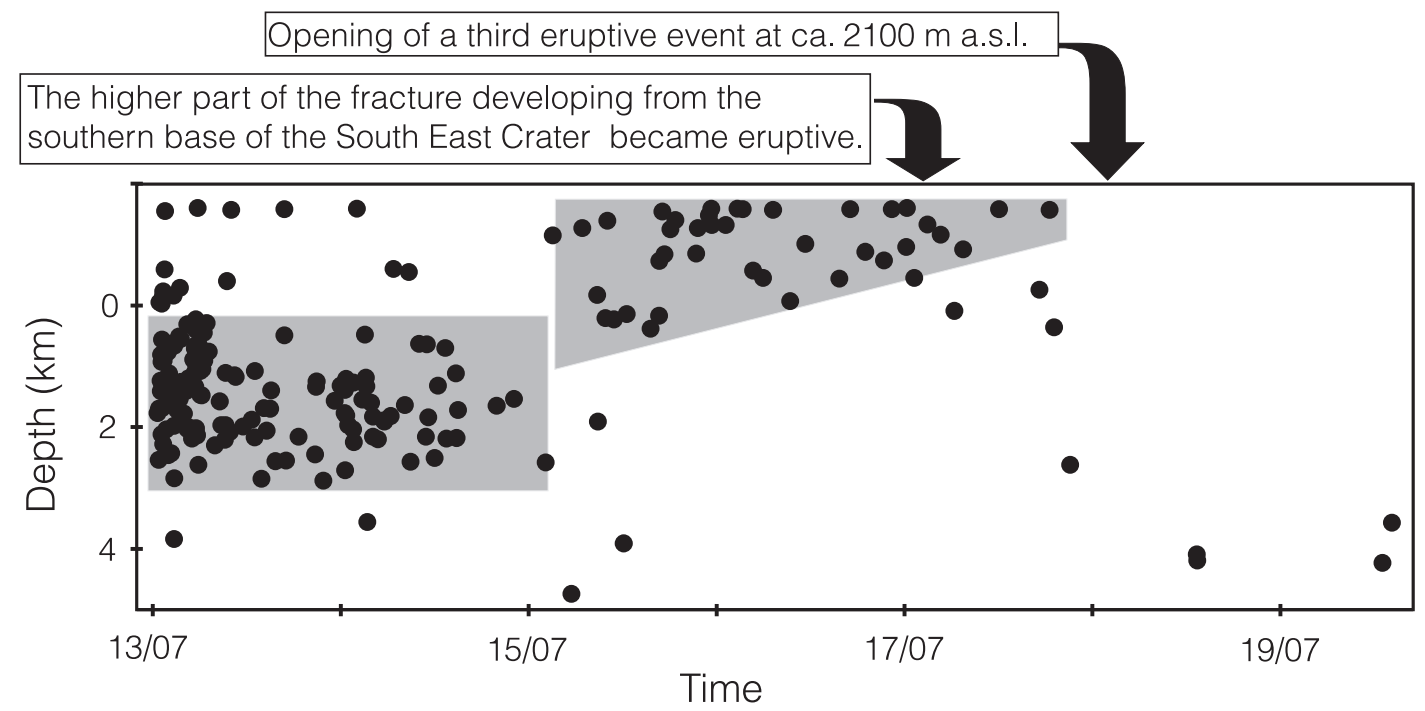

Fig. 5. Time upward migration of earthquake foci, and comparison with the eruptive phenomena. 
propagation and/or the geometric complexity (several digitations) of the dike, may explain the observed strike-slip and transtensive rupture mechanisms (sub-horizontal $P$-axes). A complex dike geometry is suggested by field evidence, specifically, discrete linearly distributed vents, rather than a unique long eruptive fracture. Finally, the evidence of a unique stress source is suggested by ground deformation results (Bonaccorso et al., 2002) and is well supported by the axi-symmetric orientation of $P$-axes for the two «peripheral» seismic volumes (areas A and $\mathrm{C}$ of fig. 4). This stress source is the nearvertical, N-S trending dike emplaced a few kilometres south of the summit region, prior to the onset of eruption.

\section{Acknowledgements}

We wish to thank Enzo Boschi for his continuous encouragement. Massimo Cocco and an anonymous reviewer are acknowledged for their useful suggestions.

\section{REFERENCES}

Barberi, G., O. Cocina, G. Neri, E. Privitera and S. SPAMPINATO (2000): Volcanological inferences from seismic strain tensor computation at Mt. Etna Volcano, Sicily, Bull. Volcanol., 62, 318-330.

BonACCORSO, A. (2001): Mt. Etna volcano: modelling of ground deformation patterns of recent eruptions and considerations on the associated precursors, J. Volcanol. Geotherm. Res, 109, 99-108.

BonACCORSO, A. and D. PATANE (2001): Shear response to an intrusive episode at Mt. Etna volcano (January 1998) inferred through seismic and tilt data, Tectonophysics, 334, 61-75.

Bonaccorso, A., F. Ferrucci, D. PATANÈ and L. Villari (1996): Fast deformation processes and eruptive activity at Mount Etna (Italy), J. Geophys. Res., 101, 17,46717,480 .

Bonaccorso, A., M. Aloisi and M. Mattia (2002): Dike emplacement forerunning the Etna July 2001 eruption modelled through continuous tilt and GPS data, Geophys. Res. Lett., 29 (13), 10.1029/2001GL014397.

Bonaccorso, A., S. D'Amico, M. Mattia and D. PATANÈ (2003): Intrusive mechanisms at Mt. Etna forerunning the July-August 2001 eruption, Pure Appl. Geophys. (in press).

Chiarabba, C., A. Amato, E. Boschi and F. Barberi (2000): Recent seismicity and tomographic modeling of the Mount Etna plumbing system, J. Geophys. Res., 105, 10,923-10,938.

Cocina, O., G. Neri, E. Privitera and S. SPAMPINATO (1998): Seismogenic stress field beneath Mt. Etna (South Italy) and possible relationships with volcano-tectonic features, J. Volcanol. Geotherm. Res., 83, 335-348.

De Natale, G., A. Ferraro and J. VirieuX (1991): A probability method for local earthquake focal mechanisms, Geophys. Res. Lett., 18, 613-616.

FERRUCCI, F. and D. PATANÈ (1993): Seismic activity accompanying the outbreak of the 1991-1993 eruption of Mt. Etna (Italy), J. Volcanol. Geotherm. Res, 57, $125-135$.

GRESTA, S. (1995): Sismicità del versante orientale dell'Etna: implicazioni vulcano-tettoniche, in Proceedings of the Meeting Progetto Etna 1993-1995: Stato di Avanzamento delle Ricerche, edited by F. FERRUCCI and F. INNOCENTI, 89-92.

Gresta, S. and G. PAtanè (1987): Review of seismological studies at Mount Etna, Pure Appl. Geophys., 125, 951-970.

HiLL, D.P. (1977): A model for earthquakes swarms, J. Geophys. Res., 82, 1347-1352.

Hirn, A., A. Nercessian, M. SAPIN, F. FerruCCI and G. WITTLINGER (1991): Seismic heterogeneity of Mt. Etna: structure and activity, Geophys. J. Int., 105, 139-153.

LAHR, J.C. (1989): HYPOELLIPSE/VERSION 2.0*: a computer program for determining local earthquake hypocentral parameters, magnitude, and first motion pattern, U.S. Geol. Survey Open-File Report 89/116, pp. 81.

Laigle, M., A. HiRn, M. SAPIn, J.C. LePine, J. DiaZ, J. Gallart and R. NicOlich (2000): Mount Etna dense array local earthquake $P$ and $S$ tomography and implications for volcanic plumbing, J. Geophys. Res., 105, 21,633-21,646.

LANZAFAME, G., M. Neri, M. Coltelli, L. LodATO and D. RUST (1997): North-south compression in the Mt. Etna region (Sicily): spatial and temporal distribution, Acta Vulcanol., 9, 121-133.

Matsumura, S., T. OHKubo and I. Masajiro (1991): Seismic swarm activity in and around the Izu Peninsula preceding the volcanic eruption of July 13, 1989, J. Phys. Earth, 39, 93-106.

NAKAMURA, K. (1977): Volcanoes as possible indicators of tectonic stress orientation; principle and proposal, J. Volcanol. Geotherm. Res., 2, 1-16.

PATANÈ, D. and E. PRIVITERA (2001): Seismicity related to 1989 and 1991-93 Mt. Etna (Italy) eruptions: kinematic constraints by FPS analysis, J. Volcanol. Geotherm. Res., 109, 77-98.

Patane, D., E. Privitera, F. Ferrucci and S. Gresta (1994): Seismic activity leading to the $1991-93$ eruption of Mt. Etna and its tectonic implications, Acta Vulcanol., 4, 47-56.

Patanè, D., C. Chiarabba, O. Cocina, P. De Gori, M. MORETTI and E. BOSCHI (2002): Tomographic images and $3 \mathrm{D}$ earthquake locations of the seismic swarm preceding the $2001 \mathrm{Mt}$. Etna eruption: evidence for a dyke intrusion, Geophys. Res. Lett., 29 (10), 10.1029/ 2001 GL014391.

REASENBERG, P.A. and D. OPPENHEIMER (1985): FPFIT, 
FPPLOT, and FPPAGE: FORTRAN computer programs for calculating and displaying fault plane solutions, U.S. Geol. Surv. Open File-Rep. 85/739, pp. 109.

RESEARCH STAFF OF INGV-CT (2001): Multidisciplinary approach yields insight into Mt. Etna eruption, Eos, Trans. Am. Geophys. Un., 82, 653-656.

RUST, D. and M. NERI (1996): The boundaries of large-scale collapse on the flanks of Mount Etna, Sicily, in Volcano Instability on the Earth and Other Planets, edited by W.J. McGuire, A.P. Jones and J. NeubERG, Geol. Soc. London, Spec. Publ., 110, 193-208.

SHAw, H.R. (1980): The fracture mechanisms of magma transport from the mantle to the surface, in Physics of Magmatic Processes, edited by R.B. HARGRAVES (Princeton Univ. Press), 201-264.

THURBER, C. and A.E. GRIPP (1988): Flexure and seismicity beneath the south flank of Kilauea volcano and tectonic implications, J. Geophys. Res., 93, 4271-4278.

Zollo, A. and P. BERNARD (1991): Fault mechanism from near-source data: joint inversion of $S$ polarizations and $P$ polarities, Geophys. J. Int., 104, 441-451.

\section{(received August 27, 2002;} accepted May 15, 2003) 